\section{Clinical \\ characteristics of pigment dispersion syndrome in Chinese patients}

G Qing, N Wang, X Tang, S Zhang and H Chen

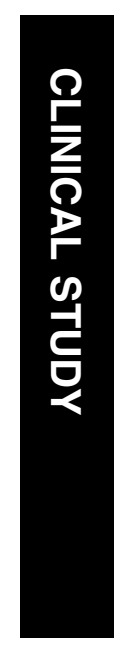

posterior peripheral lens surface. ITDs are uncommon in Chinese patients with PDS. Eye (2009) 23, 1641-1646; doi:10.1038/eye.2008.328; published online 7 November 2008

Keywords: pigment dispersion syndrome; Chinese; clinical findings

\section{Introduction}

Pigment dispersion syndrome (PDS) is an ocular disorder characterized by melanin pigment granule liberation from the iris pigment epithelium (IPE). The released pigment granules are carried by aqueous convection currents and deposit on anterior segment structures including the corneal endothelium, iris surface, trabecular meshwork (TM), lens surfaces, and zonules. Accumulation of pigment in the TM may lead to increased resistance of aqueous humour outflow, and result in the development of pigmentary glaucoma (PG). ${ }^{1,2}$

Earlier studies have shown that the prevalence and clinical features of PDS may vary across racial groups. The prevalence of PDS among adult whites is as high as $2.45 \%$. $^{3}$ Typical and classic clinical findings in white PDS patients include the triad of Krukenberg spindle, spoke-like midperipheral iris transillumination defects (ITDs), and homogenous heavy TM pigmentation, usually found in young myopic male patients. ${ }^{4-7}$ The prevalence of PDS in blacks $>7$ years old was calculated to be $0.167 \% \pm 0.013 .{ }^{8}$ The spectrum of clinical signs in black PDS patients is narrower than that of typical and classic type in whites. Some clinical signs that are consistently present in white patients such as ITDs and anterior iris stromal pigment dusting are, however, not as common in blacks. ${ }^{8-13}$ To characterize the clinical features of PDS in
Beijing Tongren Eye Centre, Beijing Tongren Hospital, Capital Medical University, Beijing, P.R.China

Correspondence: N Wang, Beijing Tongren Eye Centre, Beijing Tongren Hospital, Capital University of Medical Science,

No 1, Dong Jiao Min Xiang Street,

Dong Cheng District, Beijing 100730,

P.R.China

Tel: + 86105826 9919;

Fax: + 861058269920 .

E-mail: wningli@

trhos.com

Received: 17 January 2008 Accepted in revised form: 26 September 2008 Published online: 7 November 2008

This study was presented at Asian Oceanic Glaucoma Society 2007 Bangkok, 2-4 December 2007 Financial/conflict of interest: None 
Chinese, we carried out a prospective observational investigation on a consecutive series of 18 Chinese patients identified as having PDS according to the identical diagnostic criteria.

\section{Patients and methods}

All outpatients presenting for care at the glaucoma specialty clinic at Beijing Tongren Eye Centre, Beijing, from May 2006 to April 2007 were evaluated for PDS, if the patient had any one of the following signs: corneal endothelial pigmentation, anterior iris stromal pigment dusting, ITDs, posterior iris bowing, increased TM pigmentation, and pigment granule dusting on lens zonules or peripheral posterior surface. Detailed ophthalmic examinations included visual acuity measurement, IOP measurement, refraction, slit-lamp biomicroscopy pre- and postmydriasis, gonioscopy, funduscopic examination, and automated Humphrey SITA standard 30-2 visual field test. Systemic and ocular medical history of each subject was also recorded. All clinicians attended lectures on the clinical features of PDS in different racial groups and how to detect subtle clinical signs of PDS in pigmented racial patients before the study.

TM pigmentation was graded according to Scheie's grading system. Corneal endothelial pigment dusting was described as Krukenberg spindle, diffusive pattern, or none. If the patient had received antiglaucoma medications before the examination, the IOP measured before medication was taken as the initial IOP. Slit-lamp examination, gonioscopy, and funduscopic evaluation of the optic disk of all patients were performed and graded by the same doctor (QGP) to avoid interphysician bias.

Diagnostic criteria for PDS included at least two of the following three signs: Krukenberg spindle, homogenous moderate-to-heavy ( $\geqslant$ Scheie II) TM pigmentation, and any degree of zonular, and/or lenticular pigment granule dusting. Patients with a history of uveitis, trauma, earlier ocular surgery or anterior segment laser treatment, or any evidence of exfoliation material were excluded. Patients with PDS were diagnosed with PG, if they had two or more of the following findings: initial IOP $>21 \mathrm{~mm} \mathrm{Hg}$, glaucomatous optic nerve damage (increased cupping or abnormal disk appearance), or glaucomatous visual field loss.

We certify that all applicable institutional and governmental regulations concerning the ethical use of human patients were followed during this research.

\section{Results}

Eighteen patients (12 males and six females) were identified as having PDS out of 94 PDS suspects in the glaucoma specialty clinic according to the diagnostic criteria. A total of 1632 outpatients were examined in the glaucoma specialty clinic during the 1-year period of time. Mean age of the PDS patients was $35.5 \pm 7.0$ years (range, 22-49). The average age for male and femalepatients were $35.7 \pm 6.9$ (range, 22-48) and $35.2 \pm 8.0$ (range, 26-49) years, respectively. Male-tofemale ratio was $2: 1$. Demographic and clinical data were summarized in Table 1.

All patients except two eyes of the two patients had myopia of $-0.5 \mathrm{D}$ or greater, with mean refractive error of $-5.20 \pm 5.79$ spherical equivalent dioptres (range, $-24.75 \pm 0.5$ ). Seventeen of eighteen patients had increased initial IOP of $>21 \mathrm{~mm} \mathrm{Hg}$ in at least one eye at the time of diagnosis, with an average of $33.8 \pm 10.4 \mathrm{~mm} \mathrm{Hg}$ (range, 17-56).

Three patients had family history of glaucoma. Another four had family history of PDS. Case 4 was diagnosed incidentally at her daughter's (case 3) glaucoma appointment. Cases 11 and 12 were brother and sister. Six patients had been diagnosed with 'primary open angle glaucoma' before referral to the authors. All of them were taking antiglaucoma medications at the time of evaluation for PDS. Only six of the PDS patients had symptoms, which were mostly occasional blurred vision accompanied with fullness of the affected eye.

Eleven patients $(61.1 \%)$ had Krukenberg spindles, which were bilateral in eight and unilateral in three. The typical appearance of Krukenberg spindle in these patients was somewhat more like a 'triangle', rather than a spindle (Figure 1a). Of the remaining seven, three had trace diffuse corneal endothelial pigmentation and four had no corneal pigment dusting.

All but one of the patients had various extent of posterior bowing of the midperipheral iris, shown with a thin concave slit beam on the surface of the iris. The slit beam was projected vertically through the centre of the pupil at 30-45 degrees. However, the configuration of the iris of case 18 was regular. He had Krukenberg spindle in the left eye and increased TM pigmentation as well as lenticular dusting with pigment granules in both eyes. No patients exhibited diffuse anterior iris stromal pigment granule dusting, except for trace cluster of pigment granules on inferior surface of the iris in three of the patients.

Typical spoke-like radial ITDs were not discerned in any of the patients. In two patients (cases 3 and 15), the most myopic of the group, isolated short slit-like transillumination defects were visualized in iris crypts.

Homogeneous TM pigmentation and pigment granule dusting on lens zonules and/or peripheral posterior lens surface were seen in all patients. Heavy, homogeneous TM pigmentation around the anterior chamber angle like 
Table 1 Data of patients with clinical signs consistent with PDS

\begin{tabular}{|c|c|c|c|c|c|c|c|c|c|c|c|c|c|}
\hline Case number & $\begin{array}{l}\text { Age (years)/ } \\
\text { gender }\end{array}$ & Family history & $V A$ & $B C V A$ & $\begin{array}{l}\text { Refraction } \\
\text { (SED) }\end{array}$ & $\begin{array}{l}\text { Initial IOP } \\
(m m \mathrm{Hg})\end{array}$ & $C / D$ & $\begin{array}{l}\text { Corneal } \\
\text { endopig. }\end{array}$ & TM pig. & ITDs & $\begin{array}{l}\text { Lenticular/ } \\
\text { zonular pig. }\end{array}$ & $\begin{array}{l}\text { Anteriror Iris stromal } \\
\text { pigment dusting }\end{array}$ & $\begin{array}{l}V F \\
\text { defect }\end{array}$ \\
\hline \multirow[t]{2}{*}{1} & \multirow[t]{2}{*}{$36 / \mathrm{M}$} & \multirow[t]{2}{*}{ None } & 0.03 & 1.0 & -8.00 & 41 & 0.9 & KS & 4 & None & 3 & None & Yes \\
\hline & & & 0.04 & 1 & -7.75 & 48 & 0.8 & KS & 4 & None & 3 & None & Yes \\
\hline \multirow[t]{2}{*}{2} & \multirow[t]{2}{*}{$31 / F$} & \multirow[t]{2}{*}{ None } & 0.1 & 1 & -1.50 & 49 & 1 & KS & 4 & None & 1 & None & Yes \\
\hline & & & 0.3 & 1 & -1.50 & 39 & 0.8 & KS & 4 & None & 1 & Trace & Yes \\
\hline \multirow[t]{2}{*}{3} & \multirow{2}{*}{$26 / F$} & \multirow{2}{*}{ PDS } & 0.05 & 0.5 & -10.75 & 31 & 0.6 & KS & 3 & Trace & 4 & None & Yes \\
\hline & & & 0.01 & 0.1 & -12.50 & 48 & 0.9 & KS & 4 & Trace & 4 & None & Yes \\
\hline \multirow[t]{2}{*}{4} & \multirow[t]{2}{*}{$49 / \mathrm{F}$} & \multirow{2}{*}{ None } & 0.4 & 1.2 & 0.50 & 18 & 0.4 & KS & 3 & None & 1 & None & No \\
\hline & & & 0.2 & 1 & -0.75 & 17 & 0.4 & None & 3 & None & 1 & None & No \\
\hline \multirow[t]{2}{*}{5} & \multirow{2}{*}{$32 / \mathrm{M}$} & \multirow[t]{2}{*}{ None } & 0.05 & 1 & -1.75 & 35 & 0.6 & KS & 3 & None & 3 & None & Yes \\
\hline & & & 0.2 & 1.2 & -1.25 & 30 & 0.3 & KS & 3 & None & 3 & None & No \\
\hline \multirow[t]{2}{*}{6} & \multirow[t]{2}{*}{$35 / \mathrm{M}$} & \multirow[t]{2}{*}{ None } & 1.2 & 1.5 & -0.25 & 25 & 0.5 & DP & 3 & None & 1 & None & No \\
\hline & & & 0.6 & 1 & -1.00 & 35 & 0.9 & DP & 4 & None & 1 & None & Yes \\
\hline \multirow[t]{2}{*}{7} & \multirow[t]{2}{*}{$40 / \mathrm{M}$} & \multirow[t]{2}{*}{ Glaucoma } & 0.3 & 1.2 & -9.50 & 17 & 0.4 & KS & 3 & None & 1 & None & No \\
\hline & & & 0.05 & 0.7 & -8.00 & 33 & 0.8 & KS & 4 & None & 1 & None & Yes \\
\hline \multirow[t]{2}{*}{8} & \multirow[t]{2}{*}{$39 / \mathrm{M}$} & \multirow[t]{2}{*}{ Glaucoma } & $\mathrm{CF}$ & 0.04 & -4.50 & 43 & 1 & None & 4 & None & 1 & None & Yes \\
\hline & & & 0.05 & 0.8 & -5.00 & 37 & 0.9 & None & 4 & None & 1 & None & Yes \\
\hline 9 & $39 / \mathrm{F}$ & None & 0.2 & 1.5 & -4.50 & 27 & 0.3 & None & 2 & None & 1 & None & No \\
\hline & & & 0.1 & 1.5 & -4.50 & 24 & 0.5 & None & 4 & None & 1 & None & No \\
\hline 10 & $32 / F$ & Glaucoma & 0.02 & 0.4 & -0.75 & 29 & 0.5 & KS & 4 & None & 1 & None & No \\
\hline & & & 0.02 & 0.6 & -0.75 & 25 & 0.5 & KS & 4 & None & 1 & None & No \\
\hline 11 & $31 / \mathrm{M}$ & PDS & CF & 0.05 & -7.00 & 31 & 1 & KS & 4 & None & 3 & None & Yes \\
\hline & & & 0.04 & 0.8 & -7.00 & 29 & 0.7 & KS & 4 & None & 3 & None & Yes \\
\hline 12 & $34 / F$ & PDS & 0.02 & 0.07 & -5.50 & 54 & 1 & KS & 4 & None & 2 & None & Yes \\
\hline & & & CF & 0.07 & -5.50 & 56 & 1 & KS & 4 & None & 2 & None & Yes \\
\hline 13 & $44 / \mathrm{M}$ & None & 0.5 & 0.7 & -0.25 & 42 & 1 & DP & 3 & None & Trace & Trace & Yes \\
\hline & & & LP & LP & -0.50 & 41 & 1 & DP & 3 & None & Trace & Trace & Yes \\
\hline 14 & $36 / \mathrm{M}$ & None & 0.02 & 0.5 & -8.00 & 32 & 1 & None & 2 & None & 1 & None & Yes \\
\hline & & & 0.02 & 0.05 & -7.50 & 37 & 1 & None & 2 & None & 1 & None & Yes \\
\hline 15 & $35 / \mathrm{M}$ & None & CF & 0.05 & -24.75 & 23 & 1 & DP & 4 & Trace & 2 & Trace & Yes \\
\hline & & & 0.05 & 0.5 & -23.75 & 27 & 1 & KS & 4 & Trace & 2 & Trace & Yes \\
\hline 16 & $48 / \mathrm{M}$ & None & 0.5 & 1.2 & -0.75 & 31 & 0.6 & DP & 3 & None & Trace & None & Yes \\
\hline & & & 0.5 & 1.2 & -1.75 & 27 & 0.9 & DP & 3 & None & Trace & None & Yes \\
\hline 17 & $30 / \mathrm{M}$ & None & 0.05 & 0.05 & -1.75 & 52 & 0.9 & KS & 4 & None & 2 & None & Yes \\
\hline & & & 0.9 & 1.2 & -0.75 & 21 & 0.3 & None & 2 & None & Trace & None & No \\
\hline 18 & $22 / \mathrm{M}$ & None & 0.4 & 1.2 & -5.00 & 27 & 0.5 & None & 2 & None & None & None & No \\
\hline
\end{tabular}

$\mathrm{IOP}=$ intraocular pressure; Corneal endopig $=$ corneal endothelial pigmentation; $\mathrm{TM}$ pig. $=$ trabecular meshwork pigmentation; $\mathrm{ITDs}=$ iris transillumination defects; $\mathrm{VF}=$ visual field; $\mathrm{HM}=$ hand motion; $\mathrm{CF}=$ counting fingers; $\mathrm{DP}=$ diffuse pattern; $\mathrm{KS}=$ Krukenberg spindle

${ }^{\mathrm{T}}$ The first and second entries indicate right and left eyes, respectively.

bEM = spherical equivalent dioptres.

dVisual field defect was designated as 'yes' when GHT in Humphrey visual field suggested 'outside normal limits,' and there was no other ocular disorder to account for the defect; it was designated 'no,' when the field was normal. 

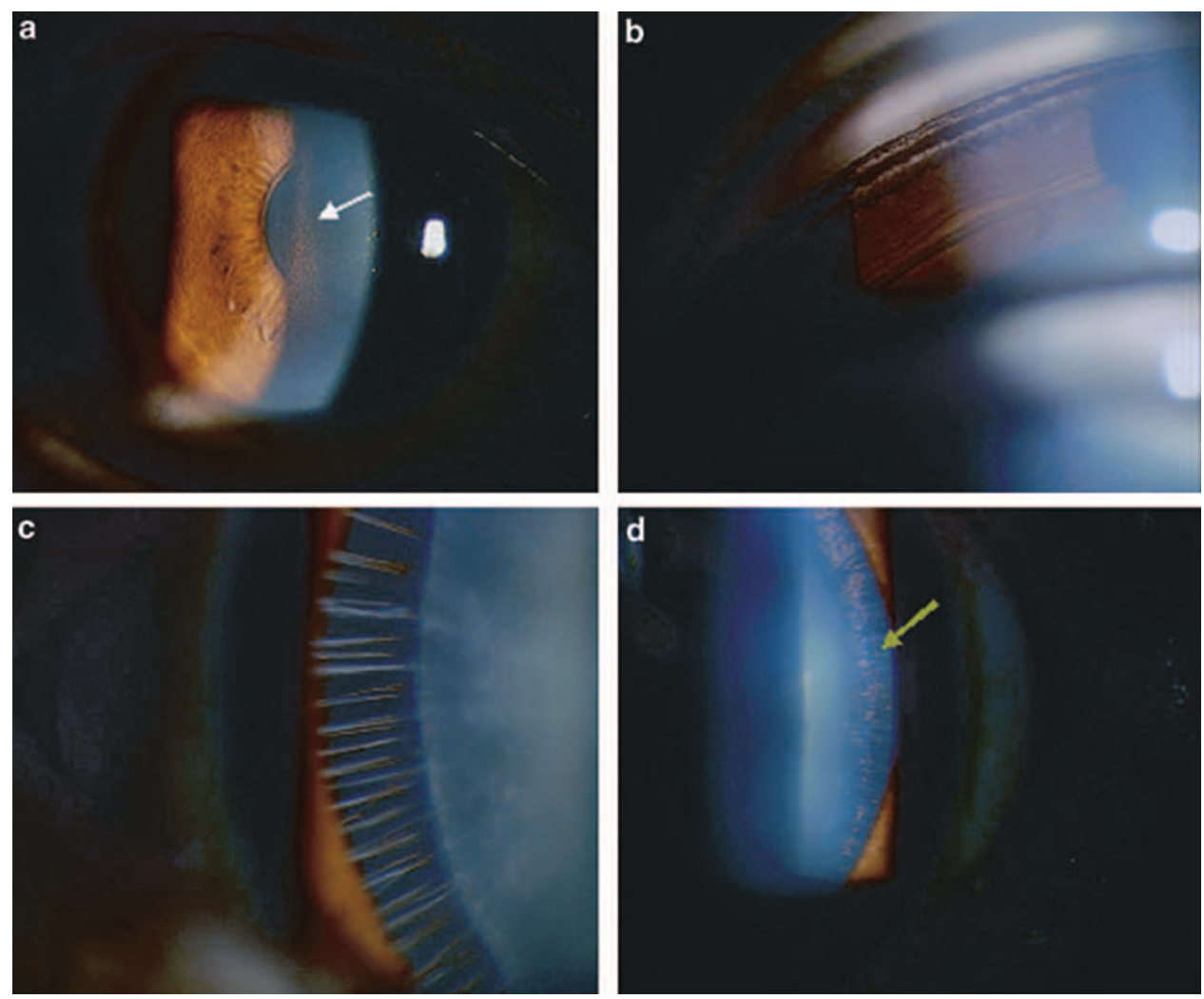

Figure 1 (a) Krukenberg spindle (white arrow) seen in case 2. It was more like a triangle rather than a spindle. (b) Homogeneous heavy trabecular meshwork pigmentation was seen in all patients. (c) Dusting of pigment granules on lens zonules. (d) Pigment accumulated at the zonular attachments to the lens, where it formed a Zentmayer ring, also referred as Scheie's line (green arrow).

a 'mascara line' band was visualized at 360 degrees in all cases on gonioscopy (Figure 1b). On biomicroscopy after mydriasis, all patients showed different extent of pigment granule dusting on lens zonules (Figure 1c) and/or posterior peripheral surface referred to as Zentmayer ring or Scheie's line (Figure 1d).

Notably, $83.3 \%(15 / 18)$ patients had manifestations of glaucoma secondary to PDS at the initial diagnosis. Ten of them were identified as having PG in both eyes. Other five were diagnosed with PG unilaterally. Two patients (cases 13 and 15) were blind at initial diagnosis of PDS. Both had severe constriction of visual field in bilateral eyes, and their spared central island of vision was less than 10 degrees.

\section{Discussion}

Two phenotypes of PDS were reported in literature before our study. One is the classic type in whites characterized by the triad of Krukenberg spindle, ITDs, and homogeneous TM pigmentation. Posterior iris bowing, pigment granule dusting on peripheral posterior lens surface and/or zonules, as well as anterior iris stromal pigment dusting are also common findings in white PDS patients. ${ }^{3,6,7,14}$ The other phenotype is the one found in blacks. One of the most significant differences between these two phenotypes of PDS is that black patients do not have midperipheral radial ITDs. ${ }^{8-13}$ Although common in white PDS patients, anterior iris stromal pigment granule dusting is rare in their black counterparts, probably because of dark irides in these patients. The results of our study have shown that the clinical features of PDS in Chinese are more like that of blacks. Homogeneous TM pigmentation and posterior lenticular and/or zonular pigment granule dusting are the most common findings in both black and Chinese PDS patients; Spoke-like midperipheral ITDs are rare in patients of these two racial groups. In all, $61.1 \%$ of Chinese PDS patients in our series have Krukenberg spindle. In black patients, this percentage was $57.1 \%{ }^{8}$ Nevertheless, there are differences in clinical findings between black and Chinese PDS patients. Posterior iris bowing was very common in Chinese PDS patients seen in $94.4 \%$ of the patients, but is rare in black patients. ${ }^{8}$ Trace clusters of pigment granules on inferior surface of the iris were discerned in three of the eighteen $(16.7 \%)$ 
Chinese patients, but was never reported in black patients.

The gender and age distribution of these Chinese PDS patients was similar to white and black PDS patients. All the patients were detected between 20 and 50 years of age, with a 2:1 male-to-female ratio.

Dark irides have been proposed to be mechanism of the lack of ITDs in black PDS patients..$^{8,11,13}$ There are a greater content of pigment granules in melanocytes and iris stroma in dark irides than in light ones. As such, they can block an IPE transillumination defect. The iris colour of Chinese is usually brown or dark brown, which results from heavy pigmentation in iris melanocytes and iris stoma. The heavily pigmented irides in Chinese may also account for the lack of ITDs in PDS. To note, the detection of ITDs in our study was based on standard slit-lamp examination in a dark room. Utilization of an infra-red imaging technique, which has demonstrated to be helpful in detecting ITDs in black PDS patients, ${ }^{11,13}$ may help pick up iris defects in Chinese patients also.

To our knowledge, there has been no published data regarding clinical features of PDS in Chinese patients and the common belief that PDS is rare in Asians is not well founded. It is likely that the hypothesis is extrapolated from very low prevalence of PDS in blacks or from clinical impression. Before this clinical research, we did have the clinical impression that PDS is not common in Chinese, also. But the results of this study alert us to think that this may not be the case. In this study, we found that PDS patients comprised 1.1\% (18 of 1632) of all outpatients in glaucoma specialty clinic of Beijing Tongren Eye Centre. This is much more common than we have previously speculated. So what has caused an underestimate of the condition? As shown in the result section, Chinese PDS patients do not have typical ITDs. The lack of this classic and striking sign of PDS is likely to distract the doctor's attention from suspecting PDS.

Six of the PDS patients in this study had been diagnosed with primary open angle glaucoma before referral to the authors. Secondly, even though Krukenberg spindle is seen in $61.1 \%$ of the Chinese PDS patients, it is subtle and hard to discern in some of them even under slit-lamp biomicroscopy because of the dark background of the highly pigmented iris, especially when the pigmentation was minimal. Furthermore, anterior iris stromal pigment granule dusting is absent in the majority of Chinese PDS patients. Whereas Krukenberg spindle, ITDs, and anterior iris stromal pigment granule dusting are all important signs that raise clinical suspicion of PDS in the ophthalmologists in clinical practice, none of them is easily detected in Chinese PDS patients. This may lead to misdiagnosis or overlook in some cases. The incomplete and subtle spectrum of clinical signs in Chinese PDS patients also leads to delayed detection of the disease.
Many PDS patients are not detected until late stage of the condition when PG or visual symptoms occur. Of note, $83.3 \%$ of patients in the study had PG, and $94.4 \%$ of them had increased IOP at their initial diagnosis of PDS. These percentages are much higher than white PDS patients. $3,6,7,14,15$

Our study has demonstrated that the most common clinical findings in Chinese PDS patients are homogeneous moderate-to-heavy TM pigmentation and pigment granule dusting on peripheral posterior lens surface and/or zonules. Typical spoke-like midperipheral ITDs are rare in this patient population. In all, $61.1 \%$ of the patients have Krukenberg spindle. And notably, $83.3 \%$ of these patients (15 of 18) had PG at the time of initial diagnosis of PDS. Thus, the finding of PDS in Chinese should alert the ophthalmologist to look for glaucoma at the initial examination.

\section{Acknowledgements}

We thank Ying Qian, MD, Cole Eye Institute, Cleveland Clinic Foundation, Cleveland, OH, USA, who provided valuable insights and suggestions for this study.

\section{References}

1 Campbell DG. Pigmentary dispersion and glaucoma: a new theory. Arch Ophthalmol 1979; 97: 1667-1672.

2 Yang JW, Sakiyalak D, Krupin T. Pigmentary glaucoma. J Glaucoma 2001; 10: S30-S32.

3 Ritch R, Steinberger D, Liebmann JM. Prevalence of pigment dispersion syndrome in a population undergoing glaucoma screening. Am J Ophthalmol 1993; 115: 707-710.

4 Sugar HS, Barbour FA. Pigmentary glaucoma: a rare clinical entity. Am J Ophthalmol 1949; 32: 90-92.

5 Scheie HG, Fleischhauer HW. Idiopathic atrophy of the epithelial layers of the iris and ciliary body. Arch Ophthalmol 1958; 59: 216-288.

6 Sheie HG, Cameron JD. Pigment dispersion syndrome: a clinical study. Br J Ophtalmol 1981; 65: 264-269.

7 Gillies WE, Brooks AM. Clinical features at presentation of anterior segment pigment dispersion syndrome. Clin Experiment Ophthalmol 2001; 29: 125-127.

8 Roberts DK, Chaglasian MA, Meetz RE. Clinical signs of the pigment dispersion syndrome in blacks. Optom Vis Sci 1997; 74: 993-1006.

9 Semple HC, Ball SF. Pigmentary glaucoma in the black population. Am J Ophthalmol 1990; 109: 518-522.

10 Roberts DK, Flynn M, Gable EM. Anterior chamber angle anomalies associated with signs of pigment dispersion in a group of black probands and their first-degree relatives. Optom Vis Sci 2001; 78: 133-141.

11 Roberts DK, Wernick MN. Infrared imaging technique may help demonstrate iris transillumination defects in blacks who show other pigment dispersion syndrome clinical signs. J Glaucoma 2007; 16(5): 440-447.

12 Roberts DK, Winters JE, Castells DD, Teitelbaum BA, Alexander CC. A cross-sectional study of Krukenberg 
spindles and pigmented lens striae in a predominately black population. J Glaucoma 2005; 14: 57-63.

13 Roberts DK, Chaglasian MA, Meetz RE. Iris transillumination defects in the pigment dispersion syndrome as detected with infrared videography: a comparision between a group of blacks and a group of nonblacks. Optom Vis Sci 1999; 7: 545-549.
14 Siddiqui Y, Ten Hulzen RD, Cameron JD, Hodge DO, Johnson DH. What is the risk of developing pigmentary glaucoma from pigment dispersion syndrome. Am J Ophthalmol 2003; 135: 794-799.

15 Lichter PR, Shaffer RN. Diagnostic and prognostic signs in pigmentary glaucoma. Trans Am Acad Ophthalmol Otolaryngol 1970; 74: 984-998. 